\title{
Análise quantitativa sobre a mortalidade precoce de micro e pequenas empresas da cidade de São Paulo
}

\section{A quantitative analysis of the premature mortality of small companies in the city of São Paulo}

\author{
Luis Fernando Filardi Ferreira ${ }^{1}$ \\ Fábio Lotti Oliva ${ }^{2}$ \\ Silvio Aparecido dos Santos ${ }^{2}$ \\ Celso Cláudio de Hildebrand e Grisi \\ Afonso Carneiro Lima²
}

\begin{abstract}
Resumo: O vigor da economia de vários países tem origem no sucesso de pequenas empresas. No Brasil, o Estado de São Paulo concentra mais da metade das empresas brasileiras de pequeno porte. Assim sendo, estudos sobre o sucesso ou o insucesso de micro e pequenas empresas têm sua relevância enaltecida. Este estudo busca apresentar uma análise quantitativa e qualitativa sobre os fatores associados à mortalidade precoce das micro e pequenas empresas. Para tanto, realizou-se uma pesquisa com os gestores de micro e pequenas empresas da cidade de São Paulo que encerraram suas atividades. Para análise quantitativa da amostra, que apresenta representatividade estatística, utilizou-se de técnicas de análise multivariada. Como principal resultado, pode-se destacar que os fatores associados à mortalidade são preponderantemente de natureza estratégica, o que contraria o senso comum que professa a insuficiência de recursos como principal motivador da falência das pequenas empresas. Tal resultado tem importância para orientar as políticas públicas, os empreendedores e as agências de fomento para a formulação de suas estratégias no sentido do desenvolvimento de competências administrativas para o sucesso das micro e pequenas empresas brasileiras.
\end{abstract}

Palavras-chave: Criação de empresas. Empreendedor. Empreendedorismo. Micro e pequenas empresas. Mortalidade de empresas.

\begin{abstract}
The economic vigor of many countries is due to the success of small businesses. In Brazil, Sao Paulo state concentrates more than half of Brazilian small businesses. Therefore, studies dealing with high or low performance of micro and small businesses are of great relevance. This study aims at presenting a quantitative and qualitative analysis of factors associated to premature mortality of micro and small businesses in the city of Sao Paulo. For the quantitative analysis of the sample, which is statistically significant, multivariate analysis was used. The main result of this investigation is that factors associated with mortality are mainly of strategic nature, contrary to the common belief that resource insufficiency is the main reason for the closing of small businesses. This result may contribute to guide public policies, entrepreneurs, and research funding agencies on the formulation of their strategies with regard to the development of managerial competencies and skills for the success of micro and small businesses in Brazil.
\end{abstract}

Keywords: Business creation. Entrepreneur. Entrepreneurship. Micro and small businesses. Business mortality.

\section{Introdução}

A dinâmica e o crescimento da economia dos países em desenvolvimento, os chamados países emergentes, dependem em grande parte da capacidade de criar empresas capazes de sobreviver, para gerar trabalho e renda para a população economicamente ativa, de maneira sustentável por longos períodos de tempo, levando estes países a alcançar um patamar superior

de produção de bens e serviços e um posicionamento mais estratégico na economia global.

No Brasil, as micro e pequenas empresas têm consolidada uma participação expressiva na economia, totalizando $99 \%$ do total de empresas, com $20 \%$ na participação do PIB nacional, segundo o IBGE (INSTITUTO..., 2010). Segundo pesquisa do SEBRAE

\footnotetext{
${ }^{1}$ Instituto Brasileiro de Mercado de Capitais - IBMEC, Av. Pres. Wilson, 118, $11^{\circ}$ andar, Centro, CEP 20030-020, Rio de Janeiro, RJ, Brasil, e-mail: fernandofilardi@gmail.com

${ }^{2}$ Faculdade de Economia, Administração e Contabilidade, Universidade de São Paulo - USP, Av. Professor Luciano Gualberto, 908, CEP 05508-010, São Paulo, SP, Brasil, e-mail: fabiousp@usp.br; sadsanto@usp.br; cchgfea1@usp.br; afonsolima@usp.br
} 
e DIEESE (SEBRAE; DEPARTAMENTO..., 2011), essas empresas respondem por quase $52 \%$ dos postos de trabalho do setor privado.

Considerando 6,1 milhões de micro e pequenas empresas, a Região Sudeste concentra $50,8 \%$ das empresas do País. A Região Sul conta com 23,3\% das empresas. A Região Nordeste possui 15,0\%, a Centro-Oeste, $7,4 \%$, e a Norte, $3,5 \%$ (SEBRAE; DEPARTAMENTO..., 2011).

Além disso, o Estado de São Paulo tem a liderança em empregos, concentra $29,6 \%$ dos postos de trabalho brasileiros, quase o mesmo número de postos de trabalho da região Nordeste $(18,4 \%)$ e Sul $(17,0 \%)$ IBGE (INSTITUTO..., 2010).

Contudo, há um fato que compromete um maior crescimento do número de empresas e, por conseguinte, da economia, que são os altos índices de mortalidade precoce de micro e pequenas empresas, gerados por diferentes elementos e condições ligadas a estas unidades produtivas. Pesquisa do SEBRAE-SP (2010) mostra que, de cada 100 empresas paulistas abertas, 27 não ultrapassam o primeiro ano de atividade. Esta proporção aumenta após cinco anos da abertura da empresa para $58 \%$.

Em vista dos diversos desafios que enfrentam os novos empreendedores e da representatividade que as empresas de micro e pequeno porte representam para o País, esta pesquisa dedica-se ao estudo da problemática acerca da extinção precoce das novas empresas, destacando os fatores associados à mortalidade relacionados ao empreendedor, à empresa e ao ambiente no qual ela se insere.

\section{Fundamentação}

\subsection{Empreendedorismo}

Timmons (1994) afirma que o empreendedorismo é uma revolução que será para o século XXI mais do que a revolução industrial representou para o século XX. Esta afirmação explica em parte por que os países em desenvolvimento têm investido tanto em programas que visem o desenvolvimento do empreendedorismo, pois, segundo Filardi (2000), com a reorientação do papel do Estado, os cidadãos se veem cada vez mais responsáveis pelo seu próprio destino e buscam reduzir a dependência da intervenção estatal na economia, criando seus próprios negócios.

Esta tendência encontra origens em alguns países considerados desenvolvidos, nos quais, conforme veremos abaixo, a criação de novas empresas tem sido considerada a base das políticas públicas e do crescimento da economia.

De acordo com Dornelas (2001), nos Estados Unidos, de 1989 até 1999, as quinhentas maiores empresas listadas pela revista Fortune eliminaram mais de cinco milhões de postos de trabalho, enquanto, nas pequenas empresas, mais de 34 milhões de novos postos de trabalho foram criados. As empresas com menos de quinhentos funcionários empregam 53\% da mão de obra privada, e são responsáveis por $51 \%$ do PIB americano. Além disso, $16 \%$ de todas as empresas norte-americanas foram criadas há menos de um ano, o que mostra uma oxigenação saudável para a economia.

Mas ao contrário do que possa parecer, o empreendedorismo não é uma moda e, segundo Dolabela (1999), ele é reflexo da evolução de uma sociedade em busca da geração do autoemprego e da autonomia profissional, de modo que hoje existe uma necessidade de se propagar conhecimentos empresariais, os quais, no passado, eram obtidos apenas pela experiência prática e não transmitida pelas escolas.

O empreendedorismo vem despertando o interesse de diversos agentes da sociedade em todo o mundo e vai além das ações do Estado, atraindo também a participação de muitas organizações multinacionais. Em 1998, a Organization for Economic Cooperation and Development - OECD publicou uma pesquisa com o objetivo de compreender o estágio de desenvolvimento do empreendedorismo nos seus países membros e identificar quais políticas poderiam ser mais prósperas para intensificar o desenvolvimento do empreendedorismo nestes países.

A partir desta iniciativa, a Comissão Europeia apresentou um relatório para o Conselho de Ministros, que, entre outras providências, propunha um compromisso para simplificar a abertura de novas empresas, facilitando o acesso ao crédito e desenvolvendo o espírito de empreendedorismo na comunidade.

O interesse dos países da Europa pelo empreendedorismo pode ser entendido por meio do estudo dos números atuais da economia americana, pois o governo federal americano investe anualmente em programas de apoio ao empreendedorismo e incentiva diversas iniciativas de governos estaduais e de organizações privadas que fomentam novas empresas no país. Por este motivo, estas iniciativas têm sido vistas como modelo por outros países que buscam aumentar o nível de sua atividade empresarial, como é o caso da Inglaterra, que criou em 1999 a Agência de Serviços para Pequenas Empresas, baseada em institutos semelhantes aos que surgiram nos Estados Unidos.

\subsection{Empreendedorismo no Brasil}

Nos últimos anos, o empreendedorismo começa a se destacar no Brasil como propulsor da economia e passa a receber maior atenção tanto do Estado quanto das empresas privadas, buscando evoluir do modelo tradicional de fluxo de recursos para um modelo mais 
dinâmico, no qual as empresas investem parte do que pagariam de impostos diretamente em projetos de iniciativa empreendedora, a exemplo do que vem ocorrendo em países desenvolvidos, em que os empreendedores são tratados como a "grande mola" da economia, como mostra a Figura 1.

Nesta figura, é apresentado o novo papel do Estado, que, por meio de leis de incentivo e isenção de impostos principalmente nas áreas da cultura, entretenimento, esportes, lazer, social e meio ambiente, vêm proporcionando o envolvimento de empresas privadas em projetos de empreendedorismo, conforme cita Filardi (2003).

Nas décadas de 1960 e 1970, o ideal de um jovem era conseguir emprego em uma grande empresa privada, nacional ou multinacional, ou ser aprovado em um concurso público, pois o salário e a estabilidade conseguidos nas grandes empresas eram convidativos, além do status e da possibilidade de crescimento dentro da organização, e aventurar-se na criação de um negócio próprio era considerado arriscado.

O empreendedorismo no Brasil começou a sobressair entre as décadas de 1980 e 1990, quando foram criadas instituições como o Serviço Brasileiro de Apoio às Micro e Pequenas Empresas - SEBRAE, para auxiliar os futuros empresários a montar seus negócios, buscando dar suporte para a legalização de empresas, além de consultorias para resolver problemas de negócios já em andamento.

Entretanto, hoje, a sociedade brasileira passa por profundas mudanças nas relações trabalhistas, com o aumento do número de profissionais qualificados, e com as alterações sofridas pela CLT, no sentido de dar maior ênfase para os acordos entre empregados e empregadores. Ao que tudo indica, há uma tendência de que o emprego tradicional esteja sendo paulatinamente substituído por outras formas de vínculo entre o capital e o trabalho, e uma das alternativas aponta para a criação de novas empresas, situação que vem ocorrendo de maneira acelerada no Brasil.

Confirmando a pujança do empreendedorismo no Brasil, um dos maiores estudos contínuos sobre a dinâmica empreendedora no mundo, promovido pela Global Entrepreneurship Monitor - GEM, mostra que o Brasil possui o maior número de empreendedores de negócios novos entre os 17 países membros do G20 que participaram da pesquisa. Além disso, nos países do BRIC, o Brasil tem a população mais empreendedora, com $17,5 \%$ de empreendedores em estágio inicial, a China teve 14,4\%, a Rússia 3,9\%, a Índia não participou da pesquisa (GLOBAL..., 2010).

\subsection{Mortalidade de empresas}

Tendo explorado as origens do empreendedorismo, suas vantagens e possibilidades, apresentam-se a seguir os principais estudos sobre os fatores contribuintes para a mortalidade de empresas, conceitos, princípios e definições sobre o tema.

\subsubsection{Estudos sobre mortalidade de empresas}

As elevadas taxas de mortalidade de empresas sempre despertaram o interesse dos pesquisadores em diversas partes do mundo, e Davis (1939) já as estudava no final da década de 1930. Sua pesquisa, realizada com base nos dados da empresa Dun \& Bradstreet, mostra que, em algumas cidades dos Estados Unidos, a mortalidade de pequenas empresas chegava a 77,6\% ao final do terceiro ano de existência. Os principais fatores citados pelo autor como responsáveis pela alta mortalidade são: a falta de mão de obra especializada, a falta de infraestrutura, a instabilidade política e

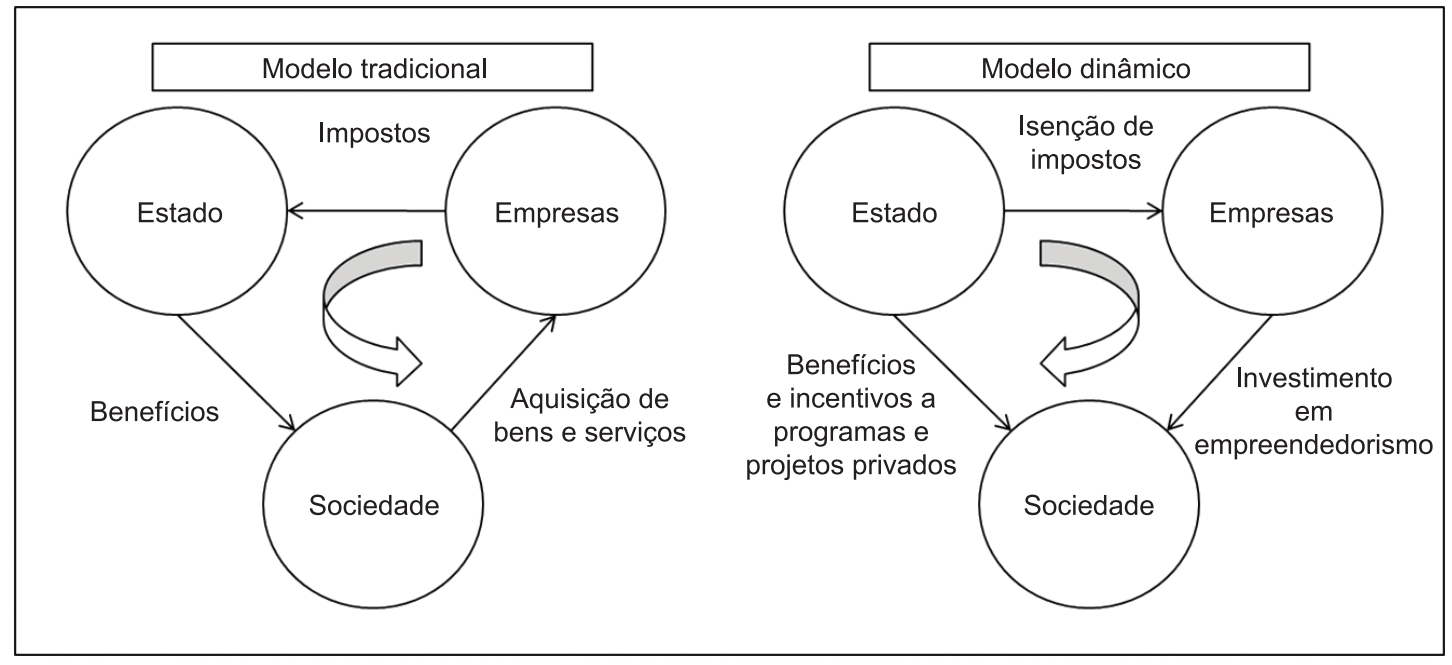

Figura 1. Fluxo do investimento em novas empresas. Fonte: Autores (2012). 
econômica, a rápida mudança de demanda por parte dos clientes.

No início dos anos 1970, Edmister (1972) buscou aplicar ferramentas para predizer a falência das pequenas empresas, baseado em análises financeiras e sofisticadas técnicas estatísticas com o objetivo de testar a hipótese de que a má gestão financeira contribui para a mortalidade precoce de pequenas empresas. Em seus estudos, ele conclui que é possível predizer a falência de uma pequena empresa com até 5 anos de antecedência, com uma certa margem de erro, e que a má gestão financeira pode ser considerada um dos principais fatores que contribuem para a mortalidade precoce.

A contribuição de Cochran (1981) deve ser ressaltada, principalmente pela sua capacidade de revisar a literatura existente até então e pela sua visão crítica dos estudos realizados, dos quais ele questiona os conceitos, definições e métodos utilizados, mostrando que há muita polêmica e complexidade no estudo da mortalidade de empresas.

Sua pesquisa identifica problemas conceituais e de definição que demonstram que não há uma uniformidade na definição do conceito de falência, para o qual existem pelo menos 5 definições conforme mostra a ilustração abaixo:

- Falência Formal: Empresas que formalizaram o seu encerramento junto aos órgãos oficiais;

- Encerramento das atividades com dívidas a credores sem baixa formal;

- Encerramento das atividades para evitar perdas e dívidas sem baixa formal;

- Empresas vendidas ou transformadas em outras atividades; e

- Descontinuidade da empresa por qualquer outra razão.

Nesta pesquisa, será adotada a definição de falência formal, principalmente pela disponibilidade de informações junto aos órgãos oficiais, especialmente as juntas comerciais dos estados a serem estudados.

Cochran (1981) explica que, dependendo do conceito que se tome por base, o resultado de uma pesquisa sobre mortalidade ou falência de empresas pode variar muito e gerar resultados pouco confiáveis, e que, quanto mais amplo o conceito, maior será a taxa de mortalidade encontrada. Apesar disso, ao revisar a literatura sobre o assunto, o autor identifica a falta de competência gerencial e a falta de experiência no ramo de negócio como fatores associados à mortalidade mais citados pela maior parte dos estudos pesquisados.

Holmes e Haswell (1989) reforçam esta visão afirmando que a competência gerencial e a falta de experiência no ramo também são consideradas fatores contribuintes para a mortalidade precoce de pequenas empresas na Austrália. Seus estudos mostram que, das 418 empresas falidas entre os anos de 1981 e
1985, 90\% tiveram sua morte associada a um dos dois fatores citados acima.

Para Adizes (1990), a criação e o desenvolvimento de um negócio só se dão pela real necessidade de consumidores empresariais ou finais a ser satisfeita e ele considera este o primeiro fator associado à mortalidade precoce de pequenas empresas, visto que muitos negócios são abertos sem ter identificado uma necessidade existente no mercado a ser satisfeita.

Os estudos de Barrow (1993) nos mostram as razões pelas quais as pequenas empresas britânicas fecham como segue abaixo:

- Falta de experiência do empreendedor;

- Falta de estratégia de marketing;

- Avaliação demasiadamente otimista do tamanho do mercado;

- Subestimar o tempo de alavancagem do negócio;

- Falta de capital de giro;

- Custo de criação da empresa muito alto;

- Capacidade produtiva menor do que a demanda;

- Escolha errada do ponto considerando maior volume de pessoas do que o real; e

- Seleção e gestão de pessoas sem competência para o negócio.

No estudo realizado por Audretsch (1995) sobre sobrevivência e crescimento, verifica-se que, num período de 10 anos, as empresas que tendem a sobreviver são aquelas que têm um tamanho maior, investem mais em inovação e, portanto, crescem mais rápido.

Além disso, segundo Bates (1995), o perfil do empreendedor influencia em grande escala a probabilidade de morte da empresa, pois, de acordo com sua pesquisa sobre empresas independentes e empresas franqueadas dos Estados Unidos, é evidenciado que empreendedores que buscam franquias são aqueles que têm menor propensão a assumir riscos, o que está ligado diretamente ao baixo retorno do negócio, levando à morte da empresa. $\mathrm{O}$ autor mostra que pequenas empresas franqueadas possuem maiores taxas de descontinuidade do negócio e menor retorno do que as empresas criadas de maneira independente.

Complementando as conclusões de Bates, os pesquisadores Birley e Niktari (1996) identificam outros 4 fatores ligados ao perfil dos empreendedores que estão associados à mortalidade de pequenas empresas:

- Perfil inflexível, resistente a mudanças e não aceita procurar ajuda externa;

- Contrata equipe de baixa competência e com baixa experiência no ramo;

- Falta de planejamento; e

- Falta de organização das operações da empresa.

Esta pesquisa encontrou alguns resultados que merecem destaque, entre eles o fato de que $41 \%$ 
dos empresários entrevistados dizem ter acreditado exageradamente na intuição e emoção, $60 \%$ confessam que não planejaram o negócio, 23\% dizem que fizeram retiradas acima do que o negócio poderia suportar e $33 \%$ não pediram auxílio externo, apesar de terem sentido dificuldades em competências que não possuíam, como área de tributos, área jurídica e de finanças.

\subsubsection{Estudos sobre mortalidade de empresas no Brasil}

Ao contrário do que ocorre em outros países, principalmente nos Estados Unidos, o Brasil não possui muitos estudos com aplicação de metodologia de pesquisa científica sobre a mortalidade de pequenas empresas e não possui uma sistematização do estudo sobre este assunto, como a Dun \& Bradstreet (2012), que realiza pesquisas periódicas sobre falência e fechamento de empresas.

Apesar disso, são encontrados alguns estudos como é o caso de Azevedo (1992) que, em sua pesquisa, afirma que entre as causas de insucesso constam: a falta de habilidade administrativa, financeira, mercadológica ou tecnológica do empreendedor, além da instabilidade econômica e da falta de crédito no mercado.

Já segundo Santos e Pereira (1995), os motivos que efetivamente têm levado muitos empreendimentos novos ao fracasso, podem ser divididos da seguinte maneira:

Quanto aos aspectos técnicos do empreendedor:

- Falta de experiência empresarial anterior; e

- Falta de competência gerencial.

$\mathrm{Na}$ área mercadológica:

- Desconhecimento do mercado; e

- Desconhecimento do produto ou serviço.

$\mathrm{Na}$ área técnico-operacional:

- Falta de qualidade nos produtos e serviços;

- Localização errada do imóvel ou do ponto;

- Problemas na relação com os fornecedores; e

- Tecnologia de produção obsoleta e ultrapassada. Na área Financeira:

- Imobilização excessiva do capital em ativos fixos;

- Política equivocada de crédito aos clientes; e

- Falta de controles de custos e de gestão financeira.

Na área Jurídica/Organizacional:

- Estrutura organizacional inadequada;

- Falta de planejamento e informações gerenciais; e

- Ausência de inovações gerenciais.

Desde 1999, o SEBRAE realiza pesquisa sobre sobrevivência e mortalidade das empresas do Estado de São Paulo e, assim, destacou em sua pesquisa inicial que os entraves mais relevantes ao êxito dos negócios no País são: o baixo nível de escolaridade e renda do empreendedor, que por falta de crédito junto às instituições financeiras, utiliza capital próprio ou da família, o que limita o crescimento da empresa e a torna vulnerável às oscilações e à sazonalidade do mercado. Além disso, a legislação também é citada como injusta, pois o tratamento dado é semelhante a todas as empresas, independente do seu tamanho (SEBRAE, 1999).

Considerando suas pesquisas dos últimos doze anos sobre sobrevivência e mortalidade das empresas do Estado de São Paulo, abertas no período de 2003 a 2007, o SEBRAE-SP (2010) destaca os seguintes motivos alegados pelos responsáveis das empresas pelo encerramento das atividades dessas empresas:

- Falta de clientes (18\%);

- Falta de capital (10\%);

- Problemas de planejamento (10\%);

- Perda do cliente único $(9 \%)$;

- Problemas com sócios $(8 \%)$;

- Encontrou outra atividade (8\%);

- Custos elevados (7\%);

- Problemas particulares (7\%);

- Falta de lucro (7\%); e

- Outros motivos (15\%).

Em outro estudo sobre micro e pequenas empresas, o SEBRAE-SP (2010) afirma que a taxa de mortalidade das empresas paulistas é de $27 \%$ no primeiro ano e, em termos acumulados, é de $37 \%$ no segundo ano e $46 \%$ no terceiro ano de atividade.

Dos 13 milhões de empreendimentos brasileiros analisados pelo GEM (GLOBAL..., 2001), 85\% não tinham condições de expansão no mercado, não usavam tecnologia de ponta e não ofertavam produtos inovadores, o que representa um baixo nível de competitividade e, portanto, comprometendo a capacidade de sobrevivência a longo prazo.

\section{Procedimentos metodológicos}

O foco desta pesquisa concentra-se na identificação dos principais fatores associados com a mortalidade de micro e pequenas empresas. Para tanto, buscou-se elaborar uma revisão teórica sobre o assunto que proporcionasse subsídios para a composição de um conjunto de fatores relacionados com o encerramento das atividades das micro e pequenas empresas. Em seguida, efetuou-se um levantamento com empresas da cidade de São Paulo e posterior análise estatística multivariada da amostra representativa.

\subsection{Variáveis de pesquisa}

Para elaborar o instrumento de pesquisas, busca-se organizar os principais fatores associados à mortalidade precoce de novas empresas, classificando e analisando estes fatores com o objetivo de levantar hipóteses que 
expliquem a alta taxa de mortalidade das empresas nos primeiros anos de atividade.

Portanto, os fatores associados à mortalidade precoce de empresas são diversos e as pesquisas já realizadas apontam em várias direções. Em resumo, com base nas causas inicialmente identificadas, podemos dividir os fatores associados à mortalidade de um novo empreendimento em três grandes blocos de fatores, conforme é demonstrado no Quadro 1.

\subsection{Coleta e tratamento dos dados}

Para proceder à coleta e análise dos dados, foi adotada uma estratégia baseada na realização de um levantamento que tratou de apurar qual a contribuição dos fatores associados para a mortalidade precoce de micro e pequenas empresas. Para isso, foi realizada uma pesquisa de campo nos meses de janeiro e fevereiro de 2006, orientada por dados e informações extraídas do cadastro de empresas extintas da junta comercial de São Paulo do ano de 2005, sobre empresas que foram constituídas nos anos de 2003, 2004 e 2005, ou seja, que sobreviveram até 3 anos.

Com base no cadastro dessas micro e pequenas empresas, considerando a população homogênea com relação aos aspectos pesquisados, realizou-se uma amostragem aleatória simples (KERLINGER, 1980, MARTINS, 2001). Executou-se um rastreamento exaustivo junto às empresas selecionadas e aos sócios, por meio de várias tentativas, tais como: telefone residencial, comercial e correio eletrônico atual dos sócios, gerentes ou pessoas que ocuparam cargos de chefia nas empresas estudadas, sendo desconsideradas as empresas cujos sócios não foram localizados, não quiseram responder ou que não chegaram a funcionar, que foram sendo substituídas por novas empresas, preservando a sequência até alcançar o número de empresas da amostra calculada acima.

Foram entrevistados os sócios das empresas, gerentes ou pessoas que ocuparam cargos de chefia nas empresas estudadas, que encerraram suas atividades com até três anos de operação, para que se tivesse uma visão mais ampliada e detalhada sobre os motivos do encerramento.

Neste estudo, foram utilizados como instrumentos de coleta de dados uma entrevista e, sempre que possível, a avaliação de documentos institucionais das empresas analisadas. O questionário foi composto por perguntas abertas e fechadas. As perguntas abertas foram desenhadas para buscar informações gerais sobre o perfil do empreendedor, do negócio e do ambiente externo. As perguntas fechadas permitiram uma análise mais profunda das informações por meio de análise descritiva e por meio de análise fatorial das variáveis das categorias associadas à mortalidade das micro e pequenas empresas: empreendedor, negócio e ambiente externo (ver Quadro 1).

Baseado em dados da JUCESP (JUNTA..., 2005), adotaram-se, como população do estudo, as micro e pequenas empresas extintas no ano de 2005, constituídas no período de 2003 a 2005. Este universo consiste de 2007 micro e pequenas empresas.

Quanto à amostra, buscou-se elaborar um estudo representativo, para tanto, calculou-se o tamanho da amostra com base nas fórmulas estatísticas que permitam generalizar os resultados obtidos para toda a população. Considerando a intenção de estimar algumas proporções da população finita na análise descritiva, utilizou-se a seguinte fórmula (Equação 1):

$$
\mathrm{n}=\mathrm{Z}^{2} \cdot \mathrm{p} \cdot \mathrm{q} /\left[\mathrm{d}^{2} \cdot(\mathrm{N}-1)+\mathrm{Z}^{2} \cdot \mathrm{p} \cdot \mathrm{q}\right]
$$

em que:

- $\mathrm{N}$ : tamanho da população $=2007$

- Z: abscissa da normal padrão = 1,96 (nível de confiança de $95 \%$ );

- p: estimativa da proporção $=0,5(0,5$ é o valor que maximiza a função $n(p))$;

- $\mathrm{q}: 1-\mathrm{p}$

- d: erro amostral=9,5\%; e

- $\mathrm{n}$ : tamanho da amostra aleatória simples $=100$.

Assim sendo, com erro amostral de 9,5\%, nível de confiança de $95 \%$, estimativa de proporção da característica estudada de 0,5, obteve-se o tamanho da amostra de 100 empresas a serem pesquisadas.

Com relação à aplicação da análise fatorial, deve-se adotar um tamanho de amostra superior a 50 observações, idealmente, maior ou igual a 100 observações. Também se espera que o tamanho da amostra seja cinco vezes superior ao número de variáveis estudadas (GORSUCH, 1983; PESTANA;

Quadro 1. Classificação dos fatores associados mortalidade.

\begin{tabular}{|l|l|l|}
\hline \multicolumn{1}{|c|}{ 1. O empreendedor } & \multicolumn{1}{|c|}{ 2. O negócio } & 3. O ambiente externo \\
\hline - Competência na gestão & - Acesso ao crédito & - Burocracia legal e fiscal \\
empresarial & - Mão de obra qualificada & - Competição dos concorrentes \\
- Experiência no ramo & - Planejamento estratégico & - Demanda dos clientes \\
- Nível de escolaridade & - Suporte jurídico e contábil & - Fornecedores, representantes, \\
- Profissionalização da relação & - Qualidade de produtos e serviços \\
com sócios & - Inovação em produtos e serviços & - Cargaidores e parceiros \\
\hline
\end{tabular}

Fonte: Autores (2012). 
GAGEIRO, 2000). No caso, como temos 15 variáveis de estudo, o tamanho da amostra deve ser superior a 75 .

A partir do questionário elaborado, aplicado, foram editadas as respostas em planilha eletrônica, identificaram-se as variáveis de pesquisa em relação aos fatores associados à mortalidade das micro e pequenas empresas, divididas em três dimensões: o empresário, a empresa e o ambiente externo. Cada dimensão é composta por fatores associados à mortalidade das micro e pequenas empresas. A dimensão o empresário agrega 4 fatores, a dimensão o negócio agrega 6 fatores e a dimensão o ambiente externo agrega 5 fatores. Para cada fator do Quadro 1, foi elaborada uma pergunta no questionário aplicado aos sócios e aos gestores das micro e pequenas empresas. As questões foram elaboradas com o objetivo de obtermos respostas quantitativas e discretas, que chamados de variáveis, de tal sorte, que a escala de medida das variáveis é razão, por exemplo, para medir o nível de escolaridade por meio do número de anos de estudo ou dicotômica para identificar se a empresa possui planejamento estratégico. Considerando as quinze questões, cada qual associada a uma variável, aplicou-se a técnica estatística de Análise Fatorial para se identificar os grupos de questões que melhor identificam os fatores associados e determinar a sua importância na explicação do fenômeno.

Segundo Hair Junior et al. (1998), os benefícios do uso da análise fatorial são: explicar relações entre variáveis e sumarizar os dados por meio de combinação linear entre as variáveis. As principais premissas para a aplicação desta técnica são: variáveis estão na escala razão (PESTANA; GAJEIRO, 2000); correlações entre as variáveis são devidas aos fatores que elas compartilham; cada variável pode ser expressa como uma combinação linear dos fatores não observados.

Depois da aplicação da técnica, foram identificados dois fatores agregadores, associados às quinze variáveis originais, e depois foram feitas considerações sobre estes dois grupos de variáveis e o seu poder explicativo sobre o fenômeno de mortalidade das micro e pequenas empresas da cidade de São Paulo.

\section{Análise dos resultados}

Os estudos realizados mostram que não existe um fator específico que possa ser responsabilizado isoladamente pelo encerramento precoce das atividades de uma empresa, entretanto é possível perceber que os fatores associados à mortalidade são bastante interligados e dependem em grande parte da atuação do empreendedor, que tem uma tendência a influenciar sobremaneira no desempenho da empresa e sua eventual sobrevivência ou morte.

Nesta parte, serão apresentadas as principais considerações relativas ao empreendedor, à empresa e ao ambiente externo, visto que o nível de integração entre seus aspectos é praticamente indissociável.
Conclui-se que estes indivíduos têm como característica comum um nível de escolaridade que pode ser considerado alto, principalmente se comparado à média brasileira, visto que a grande maioria dos empreendedores considerados (72\%) possui pelo menos o $2^{\circ}$ grau completo.

Foi possível verificar que os empreendedores que tem maior nível de escolaridade, também buscam realizar cursos de gestão empresarial, como forma de compensar a falta de experiência, e para aumentar sua competência gerencial. Esta tendência mostra também uma conscientização dos empresários com mais anos de estudo para a necessidade de fazer cursos de gestão.

Com relação à experiência, constatou-se que os empreendedores (50\%) costumam abrir a empresa sem nenhuma experiência ou com muito pouca experiência no ramo de negócio que desejam desenvolver, e que quanto menor é a experiência anterior do empresário, maior é a sua escolaridade, mostrando uma ligação inversamente proporcional entre estes dois aspectos que indicam que os empresários que estudam mais buscam substituir a falta de experiência. Foi verificado também que, conforme aumenta a experiência, há uma queda na escolaridade, mostrando uma tendência à substituição também do estudo pela prática.

Quanto à competência gerencial, a maioria significativa dos indivíduos (75\%) nunca havia trabalhado em nível de gerência ou diretoria antes de abrir a empresa, e apenas $25 \%$ haviam trabalhado na gestão de algum empreendimento, não necessariamente ligado ao ramo de negócio, antes de montar sua própria empresa.

O perfil das empresas consideradas neste estudo revela um fator comum: quase a totalidade delas (91\%) contou com apoio jurídico e contábil, o que mostra que este fator não foi determinante na mortalidade das empresas, pois, mesmo as que contaram com este apoio, não conseguiram uma sobrevivência maior.

Pode se afirmar que a qualidade e a padronização dos produtos e serviços estão diretamente associadas à mortalidade das empresas, visto que, nas empresas que sobreviveram por mais tempo, os produtos e serviços tinham características de qualidade e padronização e, nas que duraram menos tempo, boa parte dos empreendedores admitiram que seus produtos e serviços não tinham qualidade e padronização devidas.

Os empreendedores que afirmaram não ter qualidade e padronização em seus produtos alegam que manter a qualidade não é o mais difícil, mas por não investir em tecnologia e trabalharem sem apoio, um produto não ficava igual ao outro e isto comprometia a padronização.

Já com relação à inovação, também foi possível constatar associação com a mortalidade, posto que, nas empresas que sobreviveram por mais tempo, ou seja, até 3 anos, 34\% dos empresários afirmam que 
seus produtos agregavam inovação e nas que duraram menos, ou seja, até 1 ano, nenhum empresário entrevistado afirma que seus produtos tinham características de inovação.

As justificativas dos empresários para não investir em inovação foram o medo de inovar e não agradar o cliente, optando por produtos tradicionais, muitas vezes copiando o que os concorrentes líderes de mercado vendem. Os empresários citaram também a falta de flexibilidade das franquias como barreira à inovação o que limitou sua possibilidade de inovar, visto que deveria seguir as normas do franqueador.

No que diz respeito ao planejamento das empresas, verifica-se um perfil comum, pois a maioria (81\%) não realizou nenhum tipo de planejamento antes da abertura, porém aquelas empresas de maior tempo de vida realizaram algum tipo de planejamento. Já das que duraram menos, nenhuma realizou planejamento, o que reforça a orientação de que as empresas que realizaram algum tipo de planejamento duraram mais tempo e as que não realizaram nenhum tipo de planejamento têm uma tendência a encerrar suas atividades de maneira mais precoce.

Os empreendedores declararam que não realizaram planejamento porque confiam mais na experiência e na prática. Neste sentido, algumas frases se mostraram reveladoras: "o contador fazia tudo", "não precisava planejar nem acompanhar nada", "foi atrás de uma oportunidade", "não se importa com isso", "não acredita muito em planejamento, acredita mais na fé, na raça, na coragem e na intuição" e "agiu por impulso e não teve tempo de planejar". Pode-se constatar que o empreendedor não age de maneira profissional em relação à empresa que criou e que não avalia apropriadamente os riscos e oportunidades inerentes ao negócio com antecedência.

Com relação aos clientes, conclui-se que a dificuldade em conquistar e gerenciar clientes contribuiu para a mortalidade, visto que boa parte das empresas $(55 \%)$ teve dificuldade em conquistar e manter clientes. Um estudo mais aprofundado da questão mostra que o setor de serviços é o que sofre mais com as dificuldades em conquistar e manter clientes, considerando que $59 \%$ das empresas deste setor afirmaram ter tido dificuldades em conquistar ou manter clientes, percentual que cai para $52 \%$ nas empresas do setor de comércio, de acordo com cruzamento realizado.

Os principais problemas detectados com os clientes são que as empresas tinham apenas um cliente, os clientes só se importam com preço e não tem fidelidade, o ponto era inadequado e faltavam empregados para dar atendimento adequado. Outros problemas como a alta inadimplência, o baixo poder aquisitivo dos clientes, a não realização de nenhum tipo de propaganda ou atividades de marketing, e a falta de cadastro de clientes organizado podem ser destacados como fatores contributivos para a performance negativa das empresas.

A concorrência foi um ponto em que grande parte das empresas $(66 \%)$ alegou ter tido dificuldades. Levando em consideração os dados extraídos da pesquisa, ficou claro que o setor que enfrenta as maiores dificuldades com a concorrência é o setor de comércio, em que $71 \%$ dos entrevistados afirmam ter tido dificuldades com concorrentes. Já no setor de serviços, a pressão da concorrência parece ser menor, visto que apenas $59 \%$ as empresas afirmam ter tido dificuldades no setor de serviços, o que indica que a concorrência está associada à mortalidade precoce $\mathrm{e}$ que a escolha do setor da economia da empresa faz diferença significativa.

Naturalmente, a concorrência se mostra como um fator bastante associado à mortalidade precoce, ou seja, apenas empresas bem geridas sobrevivem, como é esperado numa economia capitalista de livre mercado e concorrência.

Os principais motivos e as justificativas para as dificuldades citadas pelos empreendedores foram que os concorrentes tinham melhores preços, produtos inovadores, eram maiores, com maior poder de barganha e mais organizados, investiram mais em tecnologia, tinham maior experiência no ramo, mas também eram desleais e antiéticos, sonegavam impostos e tributos e faziam cartel.

\subsection{Análise das dimensões de fatores associados à mortalidade precoce}

A segunda parte do questionário aborda o tema relacionado às três dimensões dos fatores associados à mortalidade das micro e pequenas empresas (Quadro 1). As dimensões identificadas são: o empreendedor, a empresa e o ambiente externo. Para cada qual, utilizaram-se mnemônicos: Q1 para as questões relativas ao empreendedor; Q2 para as questões relativas à empresa; e Q3 para as questões relativas ao ambiente externo. As quinze questões foram concebidas para capturar a associação dos fatores relativos às características do empreendedor, às características da gestão da empresa e às características do ambiente de negócios da empresa com a mortalidade precoce destas empresas. No entanto, de forma contraditória a quantidade de questões, variáveis, que traz mais informações sobre o fenômeno estudado, também pode dificultar a análise dos dados, por exemplo, devido à redundância informacional ou à contradição informacional. Para dirimir este conflito, utiliza-se a análise fatorial, que é um dos recursos de Data Reduction disponível no software (STATISTICAL..., 1999), que permite reduzir o número de variáveis por meio da geração de fatores, combinação linear das variáveis originais, que as substituem em parte, pois reduzem o poder explicativo 
anterior, ou seja, existe um trade-off entre o número de variáveis e o poder de explicação dos fatores. $\mathrm{Ou}$ seja, deve-se buscar um equilíbrio entre a redução das variáveis a serem analisadas e a perda de parte da informação sobre o fenômeno estudado.

Para a adoção da técnica de análise fatorial, sugere-se a verificação de algumas suposições, dentre elas (PESTANA; GAJEIRO, 2000):

- Verificar o número superior de correlações das variáveis superior a 0,30 ;

- Testar a medida de Kaiser-Meyer-Olkin (KMO), que deve ser próxima de 1 e não abaixo de 0,5; e

- Teste de esfericidade de Bartlett, verificar se a matriz Anti-Imagem é próxima da identidade.

Os dados da pesquisa apresentaram significativos índices quanto às suposições acima. $\mathrm{O}$ teste de Bartlett levou à rejeição da hipótese da matriz de correlações das variáveis ser igual à matriz de identidade, ou seja, rejeita a existência de correlação baixa entre as variáveis pesquisadas. Na tentativa de melhorar o KMO, adotou-se o procedimento de remover a variável com o menor MSA e processar novamente o teste. Também se tomou o cuidado de verificar se a sua comunalidade e seu impacto nos fatores também não eram elevados. Assim sendo, com as suposições atendidas, entende-se que análise fatorial pode ser aplicada e produzir resultados confiáveis, o que leva a crer que a suposição de distribuição normal multivariada se confirma. Portanto, com a adoção da técnica de Data Reduction, foram removidas oito variáveis originais que pouco contribuíam para a explicação do fenômeno.

Depois da adoção do procedimento descrito acima, obtiveram-se os seguintes resultados apresentados na Tabela 1.

Segundo (PESTANA; GAJEIRO, 2000), os critérios de scree plot e de KMO, valores próprios maiores que 1 , geram soluções credíveis para a escolha de fatores, quando o número de variáveis é menor que 30 ou a comunalidade das variáveis é maior que 0,6 . Adotando o método de extração de fatores, componentes principais, obteve-se a Matriz de Rotação pelo método VARIMAX (STATISTICAL..., 1999), após sua análise, obtiveram-se dois fatores agregadores (F1 e F2) relacionados com as questões fundamentadas para as três dimensões (Tabela 2).

Depois da obtenção dos dois fatores agregadores, segundo as técnicas estatísticas, deve-se identificar o significado de cada qual. Uma forma de fazê-lo é analisar as características da amostra segundo as variáveis que compõem os fatores agregadores obtidos (Tabela 3).

Tabela 1. Indicadores da análise fatorial.

\begin{tabular}{lc}
\multicolumn{1}{c}{ Indicadores } & Valores \\
\hline KMO & 0,790 \\
Comunalidade mínima & 0,577 \\
Comunalidade máxima & 0,805 \\
Comunalidade média & 0,711 \\
Eigenvalues & 3,650 e 1,329 \\
Número de variáveis selecionadas & 7 \\
Número de fatores agregadores (eigenvalues over =1) & 2 \\
Variância explicada pelos fatores agregadores & 41,407 e 29,719 \\
Total da variância explicada pelos fatores agregadores & 65,403 \\
\hline
\end{tabular}

Fonte: Autores (2012).

Tabela 2. Descrição dos fatores agregadores.

\begin{tabular}{ccclc}
\hline Fator & Dimensão & Variável & \multicolumn{1}{c}{ Questão associada } & Carga fatorial \\
\hline \multirow{2}{*}{ F1 } & & & \multicolumn{1}{c}{ Estratégia } \\
& A empresa & Q 2.3 & Ausência de Planejamento ou plano de negócios & 0,656 \\
\cline { 2 - 5 } & A empresa & Q 2.6 & $\begin{array}{l}\text { Falta de Inovação, design ou desempenho dos } \\
\text { produtos e serviços }\end{array}$ & 0,747 \\
\cline { 2 - 5 } & O ambiente externo & Q 3.2 & Dificuldade em conquistar e manter clientes & 0,889 \\
\cline { 2 - 5 } & O ambiente externo & Q 3.3 & Nível elevado de concorrência & 0,881 \\
\hline \multirow{2}{*}{ F2 } & & Q Recurso & 0,849 \\
\hline & O empreendedor & Q 1.2 & Nível de escolaridade & 0,612 \\
\cline { 2 - 5 } & O empreendedor & Q 1.3 & Competência gerencial & $-0,823$ \\
\hline
\end{tabular}

Fonte: Autores (2012). 
A análise das médias amostrais apresentadas na Tabela 3 mostra que as variáveis que compõem o fator agregador F1, Estratégia, possuem valores significativos com relação à ausência de planejamento e inovação, elevado nível de concorrência, que se entende como elementos desfavoráveis para o sucesso empresarial. A dificuldade com clientes não parece ser um fator comum aos entrevistados. No entanto, possui média importante, considerando a análise conjugada com as outras variáveis, planejamento, inovação e concorrência, mostra-se como fator importante para a mortalidade das empresas pesquisadas. Quanto às variáveis que compõem o fator agregado F2, Recursos, a falta de competência gerencial apresentou-se em elevado nível, $85 \%$, o que mostra um traço comum aos empresários que encerraram suas atividades. Conjugado com o nível de escolaridade inferior, tal resultado é aderente com as pesquisas atuais que sinalizam uma elevada complexidade do ambiente dos negócios. Salvo exceções de talentos superiores, a gestão de empresas deve ser conferida a profissionais (SEBRAE, 2010). Por outro lado, o acesso ao suporte contábil e jurídico é comum à maioria das empresas pesquisadas, tal variável não parece ser importante para explicar o fracasso empresarial, mas sim uma característica comum a todas as micro e pequenas empresas da amostra.

Com base nas análises estatísticas e na avaliação do perfil das empresas da amostra, pode-se associar aos fatores agregadores as variáveis do questionário e assim atribuir significado para cada fator agregador. No caso específico, percebeu-se uma concentração das variáveis do ambiente externo e das variáveis da empresa, relacionadas com o ambiente empresarial, no fator agregador 1 , que se nomeou como fator agregador
Estratégia. Já no fator agregador 2, percebe-se uma concentração das variáveis relativas ao empreendedor e à empresa, uma visão interna sobre a qualificação da gestão do negócio, que se nomeou como fator agregador Recurso.

O fator agregador Estratégia combina as variáveis originais associadas às questões relativas ao ambiente externo. Destaca-se a ausência de planejamento estratégico dos negócios estruturado, ou seja, as empresas inserem-se nos mercados sem a devida análise dos mercados potenciais, análise das devidas competências organizacionais, análise financeira e outras. Mesmo para algumas empresas que apresentam um esboço estratégico com certa racionalidade, percebe-se que há muito mais intuição ou experiência vivida que podem não mais refletir a realidade atual dos negócios. No âmbito estratégico, verifica-se também a insuficiência da adoção da inovação como estratégia empresarial. Como alguns estudos mostram, destaca-se Audretsch (1995), as micro e pequenas empresas que driblaram a mortalidade apresentam um índice mais elevado de inovação em seus produtos. As outras duas variáveis que mais contribuem para a mortalidade precoce das empresas são: aquisição e manutenção de clientes e nível elevado de concorrência. Estas duas variáveis do ambiente competitivo, naturalmente, constituem duas das mais importantes preocupações dos gestores das empresas de qualquer porte.

Por outro lado, o fator agregador Recurso combina variáveis originais associadas às questões relativas às características do empreendedor ou da empresa, que muitas vezes se confundem. O nível de escolaridade do empreendedor foi um fator fortemente apontado como preponderante para a mortalidade da empresa.

Tabela 3. Perfil das Micro e Pequenas Empresas Segundo os Fatores Agregadores.

\begin{tabular}{|c|c|c|c|c|}
\hline Fator & Dimensão & Variável & Questão associada & Média amostral \\
\hline F1 & \multicolumn{4}{|c|}{ Estratégia } \\
\hline & A empresa & Q 2.3 & $\begin{array}{l}\text { Ausência de planejamento ou plano } \\
\text { de negócios }\end{array}$ & $\begin{array}{l}81 \% \text { afirmaram que não fizeram } \\
\text { nenhum planejamento prévio antes } \\
\text { de iniciar o seu negócio }\end{array}$ \\
\hline & A empresa & Q 2.6 & $\begin{array}{l}\text { Falta de Inovação, design ou } \\
\text { desempenho dos produtos e serviços }\end{array}$ & $\begin{array}{l}72 \% \text { afirmaram que seus produtos } \\
\text { não possuem inovação }\end{array}$ \\
\hline & O ambiente externo & Q 3.2 & $\begin{array}{l}\text { Dificuldade em conquistar e manter } \\
\text { clientes }\end{array}$ & $\begin{array}{l}55 \% \text { indicaram dificuldades em } \\
\text { conquistar e manter clientes }\end{array}$ \\
\hline & O ambiente externo & Q 3.3 & Nível elevado de concorrência & $\begin{array}{l}66 \% \text { defrontaram-se com intensa } \\
\text { concorrência e tiveram dificuldades }\end{array}$ \\
\hline \multirow[t]{4}{*}{ F2 } & \multicolumn{4}{|c|}{ Recurso } \\
\hline & O empreendedor & Q 1.2 & Nível de escolaridade & $56 \%$ não possuem nível superior \\
\hline & O empreendedor & Q 1.3 & Competência gerencial & $\begin{array}{l}85 \% \text { nunca tiveram experiência de } \\
\text { trabalho em nível gerencial }\end{array}$ \\
\hline & A empresa & Q 2.4 & Suporte contábil e jurídico & $\begin{array}{l}91 \% \text { confirmaram ter contratado } \\
\text { suporte contábil e jurídico }\end{array}$ \\
\hline
\end{tabular}

Fonte: Autores (2012). 
A atual competitividade dos negócios demanda, paulatinamente, gestores profissionais, com formação que contemple os conceitos da administração de empresas. De maneira análoga, a competência gerencial do empresário mostrou-se decisiva para a sobrevivência das empresas. Aliada com o nível de escolaridade do empreendedor, verifica-se que os dois fatores indicam que a gestão dos negócios tende a ser cada vez mais profissional, a experiência e a vivência vão dando espaço para o conhecimento adquirido que, quando associado com as praticas, potencializam a chance das micro e pequenas empresas alcançarem a boa gestão de seus negócios. Por fim, o suporte contábil e jurídico, notadamente, terceirizado nas pequenas empresas, mostrou-se um fator importante para a sobrevivência das empresas. A carga fatorial negativa é consistente com este fato e o resultado da pesquisa amostral mostra que $91 \%$ das micro e pequenas empresas estão atentas a esta necessidade que, antes de tudo, é uma obrigação legal. Verificou-se que muitas começam informais, com o crescimento, buscam, naturalmente, a legalidade que oferece oportunidade de fornecer seus produtos e seus serviços para empresas de grande porte, de acesso a financiamento de bancos, de transparência das suas operações. No entanto, as dificuldades se erguem de maneira que o empreendedor prefere abandonar o negócio ou as suas incompatibilidades legais o levam à perda de capital e, consequentemente, ao cessar das suas atividades. Constata-se a variável ambiental legal como um fator gerador de complexidade do ambiente, o que acarreta a dificuldade da gestão dessas empresas em atender às demandas que o arcabouço jurídico-legal impõe.

Vale destacar do resultado da análise fatorial, que os dois fatores agregadores Estratégia e Recurso apresentam-se consistentes com a literatura referente aos fatores associados com a mortalidade precoce das micro e pequenas empresas. Verificou-se quantitativamente que os fatores preponderantes para a mortalidade precoce das micro e pequenas empresas estão associados às questões de natureza estratégica, como mostra a variância explicada pelo fator agregador Estratégia, cujo valor é 41\%. Quanto ao fator agregador Recurso, associado às questões voltadas à falta de condições internas para a boa gestão dos negócios, constata-se que a variância explicada por este fator é $29 \%$, que mostra sua importância, mas ainda está subordinado às questões estratégicas que podem configurar um caminho de sucesso da empresa, mesmo com as dificuldades internas. $\mathrm{Ou}$ seja, as micro e pequenas empresas que encerram suas atividades precocemente são preponderantemente influenciadas pelos fatores estratégicos da gestão.

Corroborando tal consideração, encontramos estudos neste sentido que ressaltam a relevância dos fatores de natureza estratégica sobre os fatores de natureza organizacional. Pode-se destacar a pesquisa de Bortoli Neto (1980), Bortoli Neto et al. (2001) e Bortoli Neto e Moreira Junior (2007) que confirma que $80 \%$ dos principais problemas das pequenas empresas advêm de problemas de natureza estratégica. A pesquisa GEM (GLOBAL..., 2010), realizada com especialistas sobre empreendedorismo, também sinaliza que os principais fatores citados como limitantes para o desenvolvimento de novos negócios são: falta de políticas governamentais (69\%), falta de apoio financeiro (56\%) e educação ou capacitação do empreendedor (50\%). Pode-se entender que a falta de políticas de fomento ao empreendedorismo é considerada como o fator estratégico principal para os insucessos no ambiente empresarial. Não obstante, a capacitação gerencial foi citada por metade dos especialistas como fator interno importante que limita o empreendedorismo no Brasil. Estudos internacionais também apresentam mesma orientação. Gaskill, Van Auken e Manning (1993) apresentam uma clássica pesquisa com pequenas empresas americanas que faliram no período de 1987 a 1991. A análise fatorial apresenta quatro fatores explicativos para as causas apontadas para a falência das empresas: (1) falta de conhecimento em gestão e planejamento, (2) falta de capital de giro, (3) ambiente de negócios extremamente competitivo, (4) crescimento e expansão prematuros. Uma análise mais detalhada das dezenove variáveis que compõem os quatro fatores do modelo com variância explicada de $64,5 \%$, mostra que onze variáveis relativas a questões estratégicas compõem mais de $40 \%$ da variância explicada do modelo e as outras oito variáveis compõem menos de $24,5 \%$ da variância explicada pelo modelo, assim sendo, constata-se que a falta de orientação estratégica permeia as causas da falência empresarial. Adicionalmente, Carter e Van Auken (2006), em pesquisa realizada com pequenas empresas falidas americanas, constataram que três principais fatores contribuíram para a derrocada empresarial: (1) falta de acesso a financiamento externo, (2) falta de conhecimento em gestão empresarial, (3) ameaças do ambiente de negócios. Os fatores (1) e (3) são considerados fatores externos que reforçam a importância da micro e pequena empresa possuir uma orientação estratégica. Neste mesmo sentido, uma pesquisa atual do SEBRAE-SP (2010) apresenta seis principais causas de mortalidade das empresas paulistas, sendo que, quatro causas podem ser consideradas de cunho estratégico: falta de comportamento empreendedor, ausência de um planejamento estratégico prévio, insuficiência de políticas de apoio para micro e pequenas empresas, e conjuntura econômica desfavorável ao negócio. As outras duas causas podem ser consideradas relativas à falta de recurso: deficiências na gestão empresarial e impacto dos problemas pessoais nos negócios. $\mathrm{O}$ que contraria o senso comum que advoga que a falta 
de recursos é determinante para o insucesso destas pequenas empresas.

\section{Considerações finais}

O objetivo central do trabalho foi apontar quais são os principais fatores associados com a mortalidade das micro e pequenas empresas, para tanto, buscou-se elaborar uma revisão teórica sobre o assunto que subsidiasse a composição de um conjunto de fatores relacionados com o encerramento das atividades das micro e pequenas empresas. Posteriormente, efetuou-se uma pesquisa quantitativa e qualitativa com empresas da cidade de São Paulo.

Segundo a pesquisa realizada, pode-se observar que os principais fatores associados com a mortalidade precoce das micro e pequenas empresas são:

- Ausência de planejamento ou plano de negócios;

- Falta de inovação, design ou desempenho dos produtos e serviços;

- Dificuldade em conquistar e manter clientes;

- Nível elevado de concorrência;

- Baixo nível de escolaridade do empreendedor; e

- Competência gerencial diminuta.

Vale ressaltar que o primeiro bloco de quatro fatores está intimamente ligado com as questões de natureza estratégica. Enquanto que o segundo bloco subsequente de dois fatores está relacionado com as questões de natureza organizacional. Observou-se, pela análise quantitativa, que os fatores estratégicos apresentam-se mais decisivos como motivadores da mortalidade das micro e pequenas empresas.

$\mathrm{O}$ tema ainda mostra-se atraente para o desenvolvimento de novas pesquisas dada a presença de lacunas que persistem. Destaca-se a importância de verificar as boas práticas gerenciais adotadas por empresas deste porte e identificar as competências organizacionais que determinam o sucesso destas empresas.

O resultado obtido confirma algumas pesquisas brasileiras e internacionais realizadas nas últimas décadas. Espera-se que somados possam orientar as políticas públicas, os empreendedores e as agências de fomento para a formulação de suas estratégias no sentido do desenvolvimento de competências administrativas para o sucesso das micro e pequenas empresas brasileiras.

\section{Referências}

ADIZES, I. Corporate Lifecycles: how and why corporations grow and die and what to do about it. Santa Monica: Adizes Institute, 1990.

AUDRETSCH, D. B. Innovation and Industry Evolution. Massachusetts: MIT-Press, 1995.

AZEVEDO, J. H. Como iniciar uma empresa de sucesso. Rio de Janeiro: Qualitymark, 1992.

BARROW, C. The essence of small business. Hertfordshire: Prentice Hall, 1993.
BATES, T. Analysis of Survival Rates Among Franchise and Independent Small Business Startups. Journal of Small Business Management, v. 33, n. 2, p. 26-37, 1995.

BIRLEY, S.; NIKTARI, N. Reasons for Business Failure. Leadership \& Organization Development Journal, v. 17, n. 2, p. 52, 1996.

BORTOLI NETO, A. Tipologia de problemas das pequenas e medias empresas. 1980. Dissertação (Mestrado)Faculdade de Economia, Administração e Contabilidade, Universidade de São Paulo, São Paulo, 1980.

BORTOLI NETO, A. et al. Empreendedor alerta: soluções para o negócio em dificuldades financeiras. São Paulo: Fundação Instituto de Administração, 2001.

BORTOLI NETO, A.; MOREIRA JUNIOR, A. L. Empresa Familiar: um sonho realizado. São Paulo: Saraiva, 2007.

CARTER, R.; VAN AUKEN, H. Small Firm Bankruptcy. Journal of Small Business Management, v. 44, n. 4, p. 439-512, 2006. http://dx.doi. org/10.1111/j.1540-627X.2006.00187.x

COCHRAN, A. B. Small Business Mortality Rates: A Review of the Literature. Journal of Small Business Management, v. 19, n. 4, p. 50-59, 1981.

DAVIS, H. Business Mortality: The Shoe Manufactoring Industry. Harvard Business Review, v. 17, n. 3, p. 331-339, 1939.

DOLABELA, F. O segredo de Luisa. São Paulo: Cultura, 1999.

DORNELAS, J. C. A. Empreendedorismo: transformando idéias em negócios. Rio de Janeiro: Campus, 2001.

DUN \& BRADSTREET. Disponível em: <http://www. dnb.com/>. Acesso em: 14 maio 2012.

EDMISTER, R. O. An Empirical Test of Financial Ratio Analysis for Small Business Failure Prediction. Journal of Financial and Quantitative Analysis, v. 7, n. 2, p. 1477-1493, 1972. http://dx.doi.org/10.2307/2329929

FILARDI, F. Empreendedorismo Sustentável: A Experiência do Programa Iniciativa Jovem. In: SEMINÁRIOS EM ADMINISTRAÇÃO, 6., 2003, São Paulo. Anais... SEMEAD/USP, 2003.

FILARDI, F. Os primeiros resultados do novo modelo de regulação do setor elétrico. A experiência da Light serviços de eletricidade. Revista de Administração Pública FGV, Rio de Janeiro, v. 34, n. 2, p. 153-170, 2000.

GASKILL, L. R.; VAN AUKEN, H. E.; MANNING, R. A. A factor analytic study of the perceived causes of small business failure. Journal of Small Business Management, v. 31, p. 18-31, 1993.

GLOBAL ENTREPRENEURSHIP MONITOR - GEM. Empreendedorismo no Brasil. Curitiba, 2010.

GLOBAL ENTERPRENEURSHIP MONITOR - GEM. Executive Report. Babson College Press, 2001.

GORSUCH, R. L. Factor Analysis. Hillsdale: Lawrence Erlbaum, 1983.

HAIR JUNIOR, J. F. et al. Multivariate Data Analysis. New York: Macmillan Publishing Company, 1998.

HOLMES, S.; HASWELL, S. Estimating the business failure rate: a reappraisal. Journal of Small Business Management, v. 27, n. 3, p. 68-74, Jul 1989.

INSTITUTO BRASILEIRO DE GEOGRAFIA E ESTATÍSTICA - IBGE. Estatísticas do Cadastro Central de Empresas. Brasília, 2010. 
JUNTA COMERCIAL DO ESTADO DE SÃO PAULO - JUCESP. São Paulo, 2005.

KERLINGER, F. N. Metodologia da Pesquisa em Ciências Sociais: Um tratamento conceitual. São Paulo: EPU, 1980.

MARTINS, G. A. Estatística Geral e Aplicada. São Paulo: Atlas, 2001.

ORGANIZATION FOR ECONOMIC COOPERATION AND DEVELOPMENT - OECD. Fostering the Entrepreneurship: A Thematic Review. 1998. Disponível em: <http://www.oecd.org>. Acesso em: 15 abr. 2004.

PESTANA, M. H.; GAJEIRO, J. N. Análise de Dados para Ciências Sociais: a complementaridade do SPSS. São Paulo: Sílabo, 2000.
SANTOS, S. A.; PEREIRA, H. J. Criando seu próprio negócio: como desenvolver o potencial empreendedor. Brasília: SEBRAE, 1995.

SEBRAE; DEPARTAMENTO INTERSINDICAL DE ESTATÍSTICA E ESTUDOS SOCIOECONÔMICOS - DIEESE. Anuário do trabalho na micro e pequena empresa: 2010-2011. Brasília, 2011.

SEBRAE. Estudo da mortalidade das empresas paulistas. São Paulo, 1999.

SEBRAE. Doze anos de monitoramento da sobrevivência e mortalidade de empresas. São Paulo, 2010.

STATISTICAL PACKAGE FOR SOCIAL SCIENCES - SPSS. SPSS Base 9.0 Applications Guide. Chicago: SPSS, 1999. TIMMONS, J. A. New venture creation, entrepreneurship for the 21st century. 4th ed. Irwin, 1994. 
